\title{
The wings of time
}

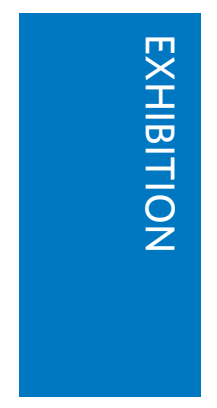

As we enter the bright, naturally lit lower ground atrium of the Institute of Physics in London, we are greeted by the two large screens that form the centre piece of Grace Weir's video installation Time Tries All Things. The screens are facing each other at an angle, like they were having a conversation. And indeed, when we sit down in front of them and put on our headphones - which conveniently drown out most of the noise from the school activity going on next door - we find ourselves in the midst of a virtual dialogue between theoretical physicists David Berman (Queen Mary University of London) and Fay Dowker (Imperial College London), each discussing a different theory about time.

The two scientists don't actually talk to each other throughout the 33-minute recording, only to the audience, and each of them only ever appears on one of the screens. They both have their own view rooted in a different school of thought about the nature of time. Berman is a string theorist, while Dowker works on quantum gravity. So, on the left you have the continuum Minkowski spacetime, on the right the discrete network of 'spacetime atoms. This distinction is also reflected in the cinematography with the camera constantly moving around Berman in what appears to be the reading room of a library and the picture discretely jumping between different perspectives of Dowker, sitting with her network drawings or standing by the window.

But that's not even half of the story: the two physicists touch on the intimate connection - one could say 'identity' between space and time. They also discuss the role of probability and disorder when something has to choose 'which way to go forward' and the uncomfortable feelings generated by the idea of a 'block universe', where past, present and future events are crystallized in a majestic, atemporal block. The very title of the work is reminiscent of the way Richard Feynman managed to quantitatively solve the puzzling temporal evolution of elementary particles: they simply 'try all things they could do, and the final result is the sum of all these options, bound together by quantum interference.

The visual - and conceptual juxtaposition of Berman and Dowker on the two screens is not the only duality in Weir's

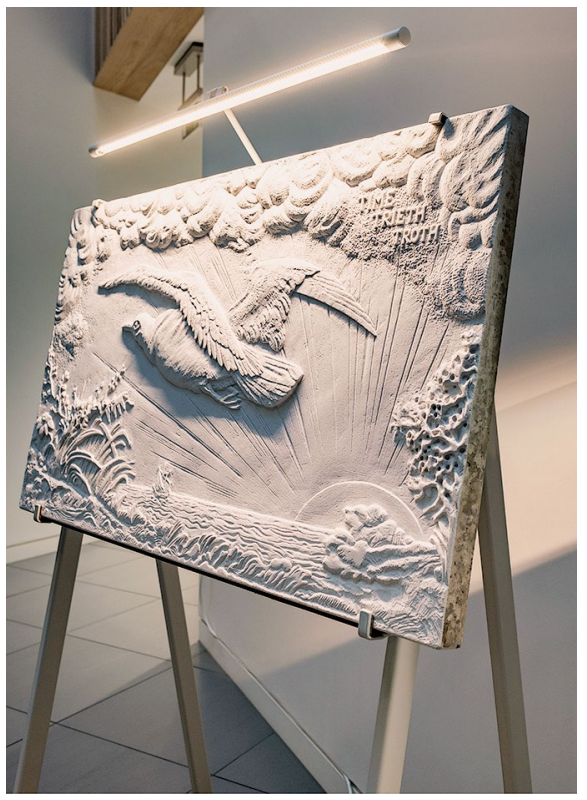

Replica of the seagull relief on the Baron de Stern clock tower at Queen Mary University of London. Credit: (c) Grace Weir

installation; duality pervades the whole work. Opposing views on the nature of time might seem like a consequence of modern physics, but have in fact been central to the debate since the days of the ancient Greek philosophers (some of whom have a sort of cameo in the video). Take Zeno of Elea and his famous paradox arguing against the reality of motion and the appropriately cynical response by Diogenes, who simply stood up and walked to prove his point. This ancient story exemplifies a general problem science often has to confront, and on which Berman touches in his narration: the description of a thing often appears at odds with the thing itself, hampered by the limits imposed on us by language and human constructs.

Time is a concept so deeply ingrained in the human experience that it is essentially impossible to come up with an intuitive definition. The theories that today's physics has to offer have certainly come a long way since the ancient Greeks, but if - like Weir - you want to convey to a wider audience what it is that modern science has to say about time and where it is currently struggling to get a grip, you really need all the help you can get.

The artist is well known for using images and sounds to explore abstract scientific and philosophical concepts such as space, time, observation and the acts of making and becoming. In Time Tries All Things, she uses her audio-visual art, intertwined with rational but conceptual - rather than mathematical - explanations to weave a gripping meditation on the meaning of time. While the scientific pictures presented by Berman and Dowker are the alternating main phrase of the piece, they each have to share some of their speaking time with another common thread - a stonemason quietly working on carving a relief of a seagull flying in front of the sun; all held together by the fabric provided by the constant (and rather eerie) background music.

Showing the making of the artwork which we later learn is actually a recreation of a carving on the clock tower at which the video begins and ends - is more than a visual element to tie Berman's and Dowker's explanations together. Its creation from a picture to a drawing to the carving of a stone slab, becomes itself a way of exploring the meaning of time, and possibly of change and identity. The carving is completed just before the video ends, but when we get up and turn to leave we find it has been there all along, right behind us, fixed like the block universe.

Weir's Time Tries All Things is not a lecture. The scientific concepts are briefly sketched, so that you don't necessarily need a scientific background to understand the points Berman and Dowker are making. The artist is not only talking to her audience's rationality, the science is intertwined with the visuals and the music to form more of a meditation on a vision of time that goes beyond what can be said through formulae - at least for those of us who are not content with staring at equations in wonder and awe.

Time Tries All Things by Grace Weir was exhibited at the Institute of Physics, London until 29 March 2019. The artist and the Institute of Physics are considering future venues for the installation around the UK and Ireland that will be announced on https://iop.org/time.

\section{Reviewed by Marco Bentivegna ${ }^{1}$ and Nina Meinzer ${ }^{2}$ \\ ${ }^{1}$ Associate Editor at Nature Communications. ${ }^{2}$ Senior Editor at Nature Communications. e-mail: marco.bentivegna@nature.com; nina.meinzer@nature.com}

Published online: 1 April 2019 https://doi.org/10.1038/s41567-019-0491-y 